\title{
FAKTOR YANG MEMPENGARUHI KEPUASAN PENGGUNA SITUS BELANJA
}

\author{
Yudi Wahyu Wibowo \\ Dosen Universitas Widya Dharma Klaten, \\ Jl. Ki Hajar Dewantoro Karanganom, Kec. Klaten Utara, Jawa Tengah \\ Sur-el : yudiwahyuwibowo@unwidha.ac.id
}

\begin{abstract}
Satisfaction is one sign of the success of a product or service in this case in the form of online shopping sites. Satisfaction assessed if users feel the achievement of a goal from the user. This study aimed to analyze the influence of variables contained in an online shopping website that quality systems, quality of information, perception of usefulness, ease of use to the user satisfaction. This research used experimental methods and quantitative data in the form of a questionnaire. The results showed that the three hypotheses were rejected and 4 received. Results of the data analysis using methods DeLone and McLean combined with Technology Acceptance Model (TAM) and PLS SEM showed that the three factors that influence user satisfaction is the quality of the system, perceived ease of use and perceived usefulness.
\end{abstract}

Keywords: DeLone and McLean,TAM,online shopping

\begin{abstract}
Abstrak : Kepuasan pengguna adalah salah satu tanda keberhasilan suatu produk ataupun layanan dalam hal ini berupa situs belanja online. Kepuasan dinilai apabila pengguna merasakan tercapainya sebuah tujuan dari pengguna. Penelitian ini bertujuan untuk menganalisis pengaruh variabel yang terdapat dalam website belanja online antara lain kualitas informasi, kualitas sistem, persepsi kegunaan, kemudahan penggunaan terhadap kepuasan pengguna. Pada penelitian ini menerapkan metode eksperimen serta menggunakan data kuantitatif berupa kuesioner. Caranya dengan membagikan kuesioner setelah responden melakukan proses skenario yang telah diberikan. Hasil penelitian menunjukan bahwa 3 hipotesis yang ditolak dan 4 diterima. Hasil analisis data menerapkan metode DeLone, W.H., and McLean, E.R. yang dikombinasikan dengan Technology Acceptance Model (TAM) serta SEM PLS menunjukan bahwa tiga faktor yang mempengaruhi terhadap kepuasan pengguna yaitu kualitas sistem, persepsi persepsi kegunaan dan persepsi kemudahan penggunaan.
\end{abstract}

Kata kunci: DeLone dan McLean,TAM,belanja online.

\section{PENDAHULUAN}

Kemampuan potensi internet sebagai sarana pemasaran dan perbiagaan senakin banyak diperbincangkan, khususnya oleh para pengguna dalam runag lingkup bidang pemasaran. Hasil diskusi tersebut menghasilkan suatu sudut pandang mengenai perdagangan elektronik, khususnya perdagangan elektronik melalui media jaringan internet. Seiring bertumbuhnya teknologi dalam dunia sistem informasi terdapat situs pemenuhan kebutuhan manusia. Website jual beli online adalah salah satunya sarana yang dibutuhkan untuk mendapatkan suatu informasi yang di butuhkan manusia sekarang ini. Banyak situs belanja yang beredar saat ini, sehingga mempermudah untuk pemenuhan kebutuhan.

Electronic Commerce atau e-commerce, adalah komponen penting dari perkembangan teknologi dalam dunia internet.[1] Penggunaan sistem e-commerce dapat menguntungkan berbagai pihak, dari konsumen, produsen maupun penjual. Dari sisi konsumen, 
menggunakan e-commerce dapat menghemat waktu dan meminimalkan biaya. Konsumen dapat memilih bermacam-macam produk dan jasa yang dibutuhkan sesuai dengan kebutuhan masing-masing selama 24 jam tanpa batasan tempat dan waktu serta bagi calon konsumen yang berbeda lokasi, tidak perlu datang langsung untuk membeli barang yang di inginkan hal ini akan lebih efisien dan efektif.[2]

Kemajuan teknologi informasi khususnya website sudah banyak mengalami perkembangan. Terdapat website yang bersifat dinamis maupun statis. Aplikasi berbasis website sudah digunakan individu, kelompok, instansi negeri maupun swasta dalam proses bisnisnya. Pemanfaatan toko online sangat berpotensi untuk menggerakkan perekonomian masyarakat jaman sekarang.[3]

Banyaknya situs jual beli maka akan banyak juga variasi website yang ada. Dalam situs jual beli terdapat faktor keberhasilan dalam proses jual belinya. memotivasi para perancang teknologi untuk dapat merancang sebuah teknologi yang bukan hanya berfungsi sesuai dengan kebergunaanya saja, namun dengan tanggung jawab harus memperhatikan kemudahan pada saat berinteraksi dengan penggunanya. Karakter dari website dengan meningkatkan isinya secara berkelanjutan yang di kembangkan oleh pengguna aplikasi berbasis website tersebut. Ditambah adanya perubahan pola penggunaan, lalu aplikasi tambahan dan layanan yang muncul dari pihak lain. Keterangan diatas menyebabkan suatu organisasi yang memakai aplikasi berbasis website sulit untuk melakukan pengukuran kualitas pengalaman pengguna website itu sendiri.[4] Selain itu bahwa ketertarikan pengguna akan kecepatan dan tersedianya aplikasi berbasis website semakin meningkat.

Dalam situasi ini meningkatkan resiko bisnis mereka apabila tidak dapat memastikan tingkat kualitas maksimal pengalaman pengguna akhir dari aplikasi website yang mereka miliki. Dengan berkembangnya aplikasi berbasis website, pengguna semakin menginginkan tampilan yang lebih atraktif, menarik dan berguna dalam proses aksesnya. Untuk mendapatkan kriteria tersebut dan lebih bervariasi dari yang lain, pengukuran yang berbasis kebergunaan aplikasi yang bertujuan mencapai kepuasan pengguna. Dalam penelitian ini menggunakan obyek 2 website belanja online. [5]

\section{METODOLOGI PENELITIAN}

Pada penelitian ini menerapkan metode penelitian eksperimen karena menggunakan instrumen penelitian berupa aplikasi website belanja online yang perlu di ujicoba di dalam laboratorium untuk mendapatkan data yang diperlukan. Obyek penelitian merupakan salah satu tujuan guna memperoleh suatu data tertentu. Dengan penjelasan mengenai penelitian yang telah di deskripsikan oleh Sugiono bahwa "obyek penelitian merupakan suatu atribut atau sifat atau nilai seseorang, obyek atau kegiatan yang memiliki karakter unik yang telah diterapkan peneliti untuk dipelajari dan dicari kesimpulannya secara mendalam". 
Metode pengumpulan berupa data primer dilakukan melalui cara metode kuesioner atau angket yang disebar supaya mendapatkan data mengenai dimensi dari konstruksi yang sedang dirancang melalui penelitian yang dilakukan ini. Partisipan di peroleh dari responden yang pernah melakukan proses jual beli online. Sedangkan untuk data sekunder dari literatur, tampilan web e-commerce yang telah didesain dengan sedemikian rupa.

\subsection{DeLone dan McLean model}

Sepuluh tahun penelitian yang lalu mengenai model penelitian terbaru untuk melakukan pengukuran keberhasilan sistem ecommerce. Dengan fokus yang utama pada penelitian dengan menerapkan usulan penambahan model. Perkembangan model kesuksesan sistem informasi dari DeLone dan McLean didasarkan pada beberapa saran dan kritik terhadap model tersebut.[6]-[8] Bagan dari model kesuksesan sistem informasi DeLone \& McLean yang baru dapat digambarkan sebagai berikut:

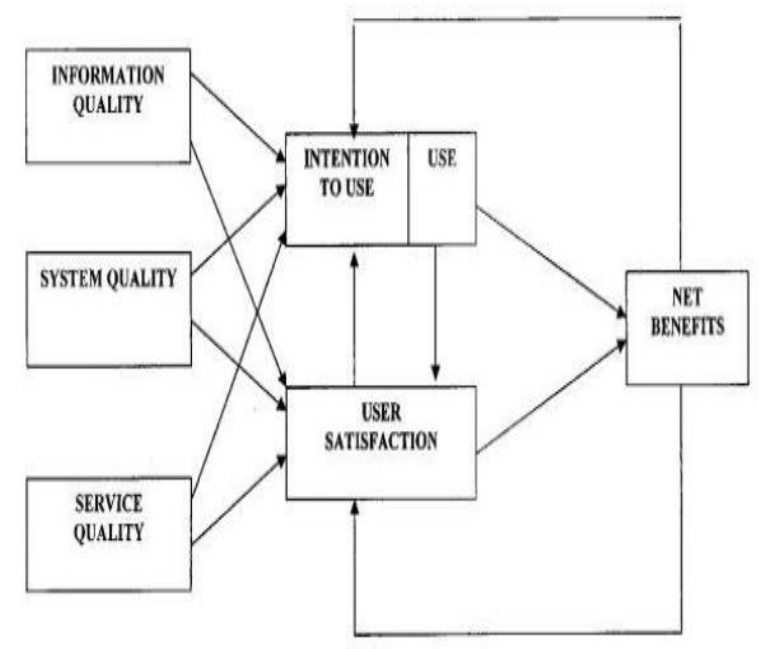

Gambar 1. Pembaharuan DeLone and McLean IS model

\subsubsection{Pengaplikasian TAM Dalam Belanja Online}

Technology Acceptance Model telah dikembangkan dan diteliti oleh Davis (1989) merupakan metode yang paling popular model penelitian guna memperoleh prediksi penggunaan dan penerimaan sistem informasi serta teknologi oleh individu. TAM telah dipelajari dan diaplikasikan secara global serta diverifikasi melalui penelitian berbeda yang meneliti perilaku individu untuk penerimaan teknologi melalui sistem informasi yang berlainan konstruksi

\subsubsection{Identifikasi Variabel}

Di dalam suatu penelitian, variabel yang dipergunakan harus dapat diukur dan didefinisikan sesuai dengan kegunaanya untuk mendukung pengujian, kemudian variabel dipresentasikan kedalam bentuk operasionalisasi variabel. Variabel penelitian dapat diartikan sebagai "suatu atribut dari obyek yang memiliki variasi tertentu yang telah dijadikan paten oleh peneliti untuk dicari kesimpulan" dari keterangan tersebut maka sesuai dengan penelitian maka penulis menggunakan 5 variabel. Variabel yang digunakan dapat dilihat pada tabel 1 .

Tabel 1. Variabel Penelitian

\begin{tabular}{|c|c|}
\hline Variabel Independent & Variabel Dependent \\
\hline 1. Kualitas Sistem & $\begin{array}{ll}\text { 1. } & \text { Persepsi } \\
& \text { Kegunaan }\end{array}$ \\
\hline $\begin{array}{l}\text { 2. Kemudahan } \\
\text { Penggunaan }\end{array}$ & $\begin{array}{l}\text { 2. Kepuasaan } \\
\text { Pengguna }\end{array}$ \\
\hline $\begin{array}{l}\text { 3. Kualitas } \\
\text { Informasi }\end{array}$ & \\
\hline
\end{tabular}

\subsubsection{Kerangka Pemikiran}

Konsep kerangka pemikiran teoritis yang diterapkan dalam penelitian ini adalah tentang 
analisis faktor yang mempengaruhi kepuasan pengguna situs belanja online. Gambar 2 menyajikan kerangka pemikiran teoritis. Variabel penelitian yang diterapkan dalam penelitian ini ialah variabel eksogen, Kualitas Informasi (Information Quality), Kualitas Sistem (System Quality), dan Kemudahan Penggunaan (Ease of Use) dan variabel endogen (dependent variable), yaitu Persepsi Kegunaan (Perceive of Usefullnes) dan Kepuasan Pengguna (User Satisfaction).

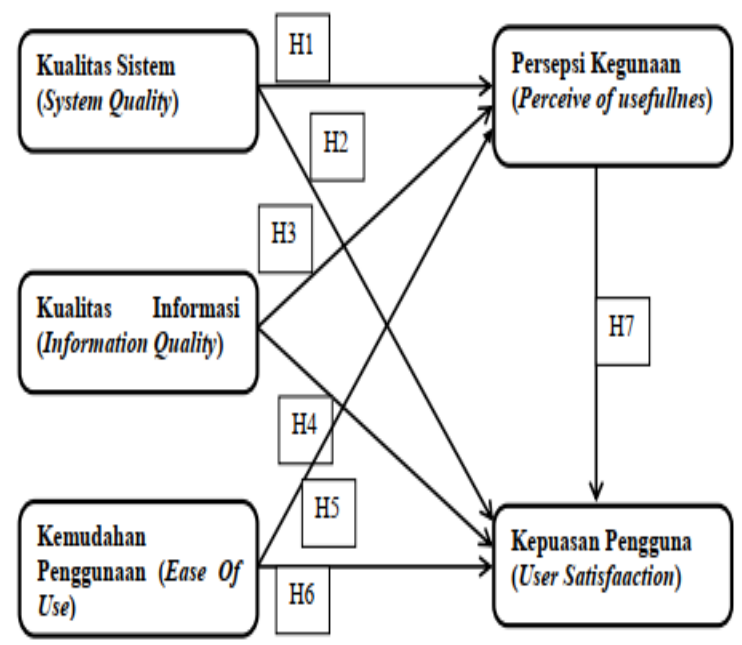

Gambar 2. Kerangka Pemikiran Teoritis

\section{HASIL DAN PEMBAHASAN}

\subsection{Hasil}

Penelitian ini menggunakan 2 website belanja online telah dirancang sedemikian rupa untuk mendapatkan data. Website yang dibuat masih merupakan prototype atau purwa rupa karena masih dalam tahap pengembangan untuk proses penyempurnaan website. Model dari website belanja online ini adalah (Bussines to Costumers) B2C bukan (Customer to Customer) C2C karena dalam penelitian ini bermaksud untuk memperoleh faktor apa saja yang berpengaruh kepada kepuasan konsumen dalam hal ini situs belanja online.

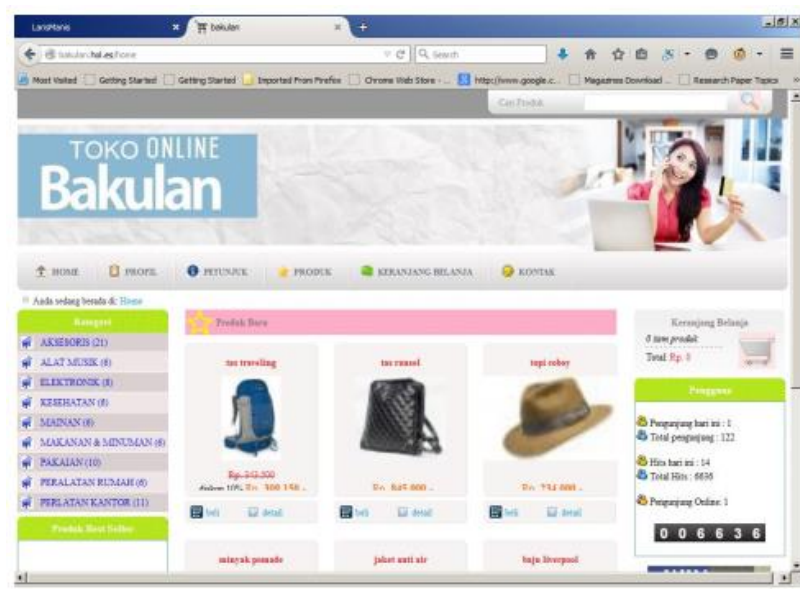

Gambar 3. Website 1

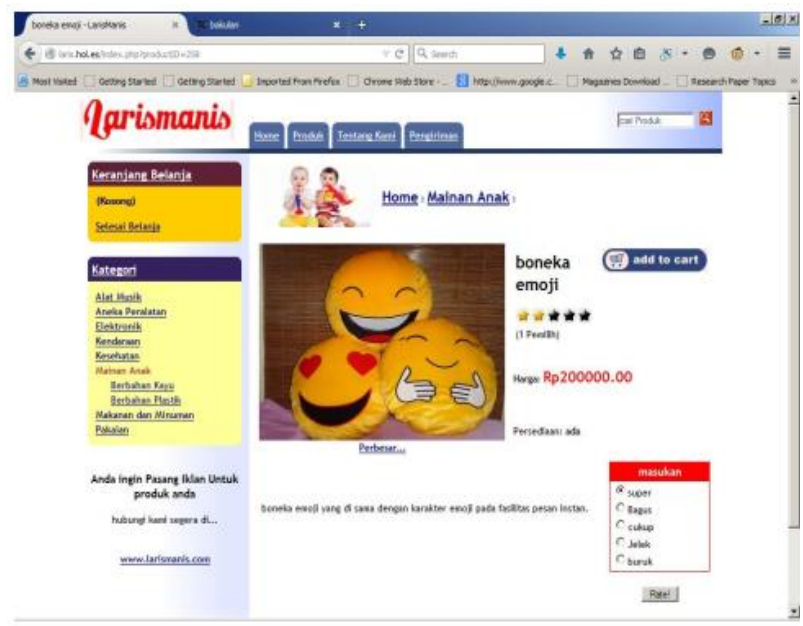

Gambar 4. website 2

\section{a) Kuesioner}

Alat penelitian merupakan perngkat yang dimanfaatkan guna mengelompokan data yang dibutuhkan dalam penelitian. Alat penelitian yang diterapkan yaitu kuesioner. Kuesioner dipergunakan untuk mengukur beberapa jenis variabel yang terdapat dalam suatu penelitian. Pengumpulan data dilakukan melalui cara menyediakan komponen pernyataan tertulis (kuesioner) kepada setiap responden (mahasiswa 
ataupun pihak yang di anggap perlu) untuk dijawab.

Data yang diperoleh dan dikumpulkan merupakan data primer yang dilakukan dengan memberikan kuesioner. Kuesioner berisikan pernyataan dari masing-masing variabel yang dimanfaatkan pada penelitian ini. Pertanyaan yang diterapkan dalam kuesioner ini menggunakan referensi skala Likert, disebutkan sebagai berikut:

1. Sangat tidak setuju (STS), dengan bobot 1 .

2. Tidak setuju (TS), dengan bobot 2 .

3. Kurang setuju (KS), dengan bobot 3.

4. Setuju $(\mathrm{S})$, dengan bobot 4 .

5. Sangat setuju (SS), dengan bobot 5 .

Untuk pertanyaan setiap masing-masing variabel dirancang berdasarkan komponen yang sudah dilakukan uji validitas dan reliabilitasnya dalam penelitian yang berkaitan dan sudah pernah dilakukan sebelumnnya. Tabel 2 menunjukkan indikator yang terdalat pada setiap variable dalam penelitian.

\section{Tabel 2. Kuesioner}

\begin{tabular}{|c|c|}
\hline $\begin{array}{l}\text { Variabel } \\
\text { Kualitas } \\
\text { Sistem }\end{array}$ & Indikator \\
\hline KS 1 & Situs sangat mudah digunakan \\
\hline KS 2 & Situs sangat handal \\
\hline KS 3 & $\begin{array}{l}\text { Situs sangat bermanfaat dalam } \\
\text { proses belanja online }\end{array}$ \\
\hline KS 4 & $\begin{array}{l}\text { Antarmuka dari sistem ini adalah } \\
\text { menyenangkan }\end{array}$ \\
\hline $\begin{array}{l}\text { Variabel } \\
\text { Kualitas } \\
\text { Informasi }\end{array}$ & Indikator \\
\hline KI 1 & $\begin{array}{l}\text { Informasi situs tersusun dengan } \\
\text { baik. }\end{array}$ \\
\hline KI 2 & $\begin{array}{l}\text { Situs menghasilkan Informasi yang } \\
\text { lengkap }\end{array}$ \\
\hline KI 3 & $\begin{array}{l}\text { Situs menghasilkan informasi yang } \\
\text { mudah dipahami }\end{array}$ \\
\hline
\end{tabular}

Informasi ini efektif dalam

KI 4

menyelesaikan tugas dan scenario

\begin{tabular}{|c|c|}
\hline $\begin{array}{l}\text { Variabel } \\
\text { Persepsi } \\
\text { Kegunaan }\end{array}$ & Indikator \\
\hline PK 1 & $\begin{array}{l}\text { Menggunakan situs guna } \\
\text { menyelesaikan perintah lebih cepat }\end{array}$ \\
\hline PK 2 & $\begin{array}{l}\text { Menggunakan situs akan } \\
\text { memaksimalkan performa pekerjaan }\end{array}$ \\
\hline PK 3 & $\begin{array}{l}\text { Menggunakan situs akan } \\
\text { meningkatkan efektivitas pekerjaan }\end{array}$ \\
\hline PK 4 & $\begin{array}{l}\text { Menemukan situs yang berguna } \\
\text { dalam pekerjaan saya }\end{array}$ \\
\hline $\begin{array}{l}\text { Variabel } \\
\text { Persepsi } \\
\text { Kemudahan } \\
\text { Penggunaan }\end{array}$ & Indikator \\
\hline PKP 1 & $\begin{array}{l}\text { Mudah untuk pengguna untuk } \\
\text { mengendalikan situs }\end{array}$ \\
\hline PKP 2 & $\begin{array}{l}\text { Saya merasa mudah mendapatkan } \\
\text { situs untuk yang saya lakukan }\end{array}$ \\
\hline PKP 3 & $\begin{array}{l}\text { Interaksi pengguna dengan situs } \\
\text { akan dimengerti dan jelas }\end{array}$ \\
\hline PKP 4 & $\begin{array}{l}\text { Mudah bagi pengguna agar menjadi } \\
\text { handal dalam menggunakan situs }\end{array}$ \\
\hline PKP 5 & $\begin{array}{l}\text { Sangat mudah untuk memperoleh } \\
\text { informasi yang pengguna butuhkan }\end{array}$ \\
\hline
\end{tabular}

\begin{tabular}{|c|c|}
\hline $\begin{array}{l}\text { Variabel } \\
\text { Kepuasan } \\
\text { Pengguna }\end{array}$ & Indikator \\
\hline KP 1 & $\begin{array}{l}\text { Secara menyeluruh, pengguna puas } \\
\text { terhadap mudahnya dengan situs ini }\end{array}$ \\
\hline KP 2 & $\begin{array}{l}\text { Pengguna akan merekomendasikan } \\
\text { hal ini untuk seseorang }\end{array}$ \\
\hline KP 3 & Situs ini nyaman untuk digunakan \\
\hline KP 4 & $\begin{array}{l}\text { Saya merasakan kenyamanan dalam } \\
\text { menggunakan situs ini }\end{array}$ \\
\hline KP 5 & $\begin{array}{l}\text { Secara keseluruhan, saya puas untuk } \\
\text { menyelesaikan tugas dalam skenario } \\
\text { ini }\end{array}$ \\
\hline
\end{tabular}

Deskripsi Responden berdasarkan jenis kelamin pada penelitian ini terdiri dari dua komponen yaitu laki-laki dan perempuan dengan rincian siswa laki berjumlah 84 siswa dan siswa perempuan berjumlah 37. Dengan status pendidikan sedang menempuh kuliah S1. 
Diagram jalur penelitian berdasarkan hipotesis dapat diihat pada gambar 5 .

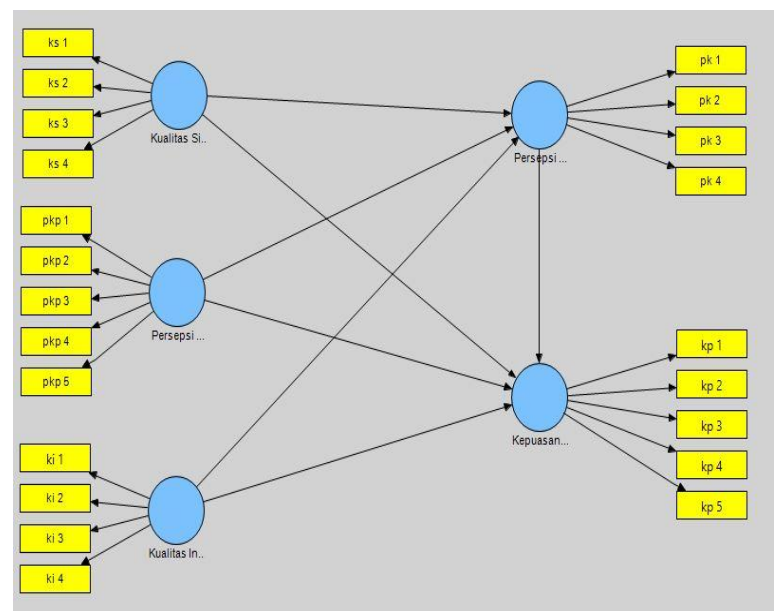

Gambar 5. Diagram penelitian

Tahap evaluasi berikutnya ialah uji reliabilitas konstruk dengan acuan menganalisis pada composite reliability atau cronbach alfa. Kriteria yang baik untuk Composite reliability atau cronbach alfa ialah diatas 0.70 . Tabel 3 memperlihatkan dan menyatakan bahwa hasil composite reliability dari setiap konstruk menghasilkan nilai diatas 0.70 . Dengan demikian semua konstruk telah memiliki nilai composite reliability yang baik.

Tabel 3. AVE dan Composite Reliability

\begin{tabular}{lll}
\hline & AVE & $\begin{array}{l}\text { Composite } \\
\text { Reliability }\end{array}$ \\
\hline $\begin{array}{l}\text { Kepuasan } \\
\text { Pengguna }\end{array}$ & 0.754831 & 0.924894 \\
$\begin{array}{l}\text { Kualitas } \\
\text { Informasi }\end{array}$ & 0.611035 & 0.824678 \\
$\begin{array}{l}\text { Kualitas } \\
\text { Sistem }\end{array}$ & 0.602593 & 0.819174 \\
$\begin{array}{l}\text { Persepsi } \\
\text { Kegunaan }\end{array}$ & 0.708283 & 0.906411 \\
$\begin{array}{l}\text { Persepsi } \\
\text { Kemudahan } \\
\text { Pengguna }\end{array}$ & 0.583411 & 0.848366 \\
\hline
\end{tabular}

Sumber: hasil olah dataPLS

\section{b) Evaluasi Struktural}

Evaluasi mengenai model struktural atau yang biasa disebut inner model dilakukan untuk mengetahui hubungan antara konstruk laten. Evaluasi ini terdiri dari dua bagian, antara lain mengenai hubungan signifikansi jalur untuk pengujian hipotesis dan nilai $R$-square dimaksudkan untuk penilaian terhadap goodness of fit model.

Hipotesis dalam penelitian ini antara lain:

H1. Kualitas sistem berpengaruh terhadap persespsi kegunaan

H2. Kualitas sistem berpengaruh terhadap kepuasan pengguna

H3. Kemudahan penggunaan berpengaruh terhadap persepsian kegunaan

H4. Kemudahan penggunaan berpengaruh terhadap kepuasan pengguna

H5. Kualitas informasi berpengaruh terhadap persepsi kegunaan

H6. Kualitas informasi berpengaruh terhadap kepuasan pengguna

H7. Persepsi kegunaan berpengaruh terhadap kepuasan pengguna

Tabel 4. Path coefficients

\begin{tabular}{llll}
\hline & $\begin{array}{l}\text { Original } \\
\text { Sample } \\
(\boldsymbol{O})\end{array}$ & $\begin{array}{l}\text { T Statistics } \\
(\mid \text { O/STERR } \mid)\end{array}$ & $\begin{array}{l}\text { Keterang- } \\
\text { an }\end{array}$ \\
\hline Kualitas & & & \\
Informasi - & 0.12944 & 1.191503 & Ditolak \\
$>$ Kepuasan & 7 & & \\
$\begin{array}{l}\text { Pengguna } \\
\text { Kualitas }\end{array}$ & & & \\
Informasi - & 0.16560 & 1.506518 & Ditolak \\
$>$ Persepsi & 0 & & \\
Kegunaan & & & \\
Kualitas & & & \\
Sistem -> & 0.30436 & 2.865044 & Diterima \\
Kepuasan & 8 & & \\
Pengguna & & &
\end{tabular}




\section{Kualitas}

Sistem ->

Persepsi

0.39136

Kegunaan

Persepsi

Kegunaan - 0.23489

> Kepuasan 2

$2.981172 \quad$ Diterima

Pengguna

Persepsi

Kemudaha

$\mathrm{n}$

$\begin{array}{llll}\text { Penggunaa } & 0.28788 & 2.642889 & \text { Diterima }\end{array}$

$\mathrm{n}->$

Kepuasan

Pengguna

Persepsi

Kemudaha

n

$\begin{array}{llll}\text { Penggunaa } & 0.14398 & 1.413726 & \text { Ditolak }\end{array}$

n $->$

Persepsi

Kegunaan

Sumber: hasil olah data PLS

Evaluasi berikut adalah goodness of fit yaitu nilai $R$-square

Tabel 5. R-Square

\begin{tabular}{lc}
\hline & R square \\
\hline Kepuasan Pengguna & 0.545195 \\
Persepsi Kegunaan & 0.331340 \\
\hline
\end{tabular}

Dari tabel 5 dapat dianalisis bahwa nilai $R$-square konstruk sikap positif (kepuasan pengguna) adalah 0.545195. Hal ini bisa diinterpretasikan bahwa mengenai variabilitas konstruk sikap positif (kepuasan pengguna) dipengaruhi terhadap konstruk persepsi kegunaan, kualitas sistem, kemudahan penggunaan, kualitas informasi $54 \%$, sisanya $46 \%$ dipengaruhi oleh konstruk lain diluar yang telah diteliti. Menurut Chin nilai ini termasuk dalam kategori hubungan kuat.

Kemudian konstruk persepsi kegunaan memiliki nilai $R$-square 0.331340 .
Interpretasinya dinyatakan bahwa variabilitas dari kostruk persepsi kegunaan yang dapat dijelaskan oleh konstruk kualitas sistem, kemudahan pengguna, kualitas informasi adalah $33 \%$. Sedangkan sisanya $77 \%$ dijelaskan oleh variabel lain di luar yang telah diteliti. Menurut Chin, nilai ini termasuk dalam ketegori moderat.

\subsection{Pembahasan}

\section{H.1 Kualitas Sistem berpengaruh} terhadap Persepsi Kegunaan

Dari hasil pengujian terhadap hipotesis ini dinyatakan bahwa kualitas sistem signifikan terhadap persepsi kegunaan. Hal ini dibuktikan dengan kondisi diterimanya hipotesis ini dimana nilai tStatistik > dari tTabel dengan nilai koefisien 0.391369. Kualitas sistem yang dirasakan mempengaruhi persepsi kegunaan. Pengaruh positif menunjukan pengaruh yang bersifat linear yaitu apabila sistemnya baik akan berpengaruh juga dengan produktifitas penggunanya. Dengan kata lain bahwa sistem yang bagus akan meningkatkan pekerjaan pengguna dalam menyelesaikan tugasnya.

\section{H.2 Kualitas Sistem berpengaruh terhadap} Kepuasan Pengguna

Pengujian mengenai hipotesis ini menghasilkan bahwa kualitas sistem berpengaruh terhadap persepsi kepuasan pengguna. Dalam hal ini validasikan dengan diterimanya hipotesis ini dimana nilai tstatistik > dari tTabel dengan besaran nilai koefisien 0.304368. Kualitas sistem yang dirasakan mempengaruhi persepsi kegunaan. Di tunjukkan dengan data bahwa pengaruh positif dari kualitas 
sistem yang handal dan dapat melakukan perintah dari pengguna akan membuat pekerjaan pengguna lebih cepat dan akan memberikan respon umpan balik berupa kepuasan terhadap pengguna setelah menggunakan sebuah sistem atau instrumen walaupun bersifat subyektif.

\section{H.3 Kemudahan Penggunaan berpengaruh} terhadap Persepsi Kegunaan

Pengujian mengenai hipotesis ini menyatakan bahwa kemudahan penggunaan berpengaruh terhadap persepsian kegunaan. Hal ini dibuktikan dengan ditolaknya hipotesis ini dengan besaran nilai tstatistik < dari tTabel dengan nilai koefisien 0.143986 . kemudahan penggunaan yang dirasakan tidak mempengaruhi persepsi kegunaan. Dalam hal ini bahwa dalam kemudahan melakukan penggunaan tidak selalu berbanding lurus dalam menyelesaikan perkerjaannya. Hal ini juga diperngaruhi oleh komposisi yang terdapat dalam situs tersebut sehingga pemahaman responden tidak selalu sama dalam menyelesaikan sebuah tugas.

\section{H.4 Kemudahan Penggunaan berpengaruh} terhadap Kepuasan Pengguna

Pengujian untuk hipotesis ini disimpulkan bahwa kemudahan penggunaan berpengaruh terhadap kepuasan pengguna. Hal ini dinyatakan bahwa diterima hipotesis ini dimana besaran nilai tstatistik > dari tTabel terhadap nilai koefisien sebesar 0.287882. Kemudahan penggunaan yang dirasakan mempengaruhi kepuasan pengguna. Kemudahan penggunaan akan berbanding lurus dengan kepuasan pengguna, dalam hal ini dikarenakan seseorang yakin percaya bahwa menggunakan sesuatu teknologi akan bebas dari usaha yang akan berakibat terhadap kepuasan pelanggan yang positif karenan seseorang akan mudah dalam menyelesaikan tugasnya.

\section{H.5 Kualitas Informasi berpengaruh} terhadap Persepsi Kegunaan

Untuk pengujian mengenai hipotesis ini menghasilkan bahwa kualitas informasi tidak berpengaruh terhadap persepsi kegunaan. Hal ini dinyatakan bahwa dengan ditolaknya hipotesis ini dimana nilai tstatistik < dari tTabel dengan besaran nilai koefisien 0.165600 . Kualitas informasi yang dirasakan tidak mempengaruhi persepsi kegunaan. Dalam hal ini kualitas yang terdapat dalam situs belanja online tidak bagus dalam perancangannya sehingga tidak memberikan efek positif terhadap persepsi kegunaan. Dapat dikatakan bahwa seseorang yang melakukan tugasnya dengan sumber informasi yang kurang bagus tidak akan meningkat pekerjaannya.

\section{H.6 Kualitas Informasi berpengaruh} terhadap Kepuasan Pengguna

Pengujian mengenai hipotesis ini dinyatakan bahwa kualitas informasi tidak berpengaruh terhadap kepuasan pengguna. Hasil ini dibuktikan dengan ditolaknya hipotesis ini dikarenakan nilai tstatistik < dari tTabel dengan nilai koefisien sebesar 0.129447. Kualitas informasi yang dirasakan tidak mempengaruhi kepuasan pengguna. Kualitas informasi yang tidak merujuk pada sistem yang menyangkut 
nilai, manfaat, relevansi, dan kebutuhan tidak memberikan dampak kepuasan terhadap pengguna walaupun kepuasan pengguna itu bersifat subyektif.

\section{H.7 Persepsi Kegunaan berpengaruh} terhadap Kepuasan Pengguna

Pengujian terakhir mengenai hipotesis ini menghasilkan bahwa persepsi kegunaan berpengaruh kepada kepuasan pengguna. Hal ini nyatakan dengan diterimanya hipotesis ini dimana nilai tstatistik > dari tTabel dengan nilai koefisien sebesar 0.234892. Persepsi kegunaan yang dirasakan mempengaruhi kepuasan pengguna. Dengan adanya pengguna yang yakin bahwa menggunakan suatu teknologi untuk menyelesaikan pekerjaannya dan meningkatkannya maka akan menghasilkan menimbukan rasa puas dalam proses tersebut.

\section{KESIMPULAN}

Berdasarkan variabel yang digunakan untuk menguji kepuasan pengguna belanja situs online tersebut adalah kualitas sistem, kualitas informasi, persepsi kegunaan, persepsi kemudahan kegunaan, dan kepuasan pengguna. Berdasarkan hasil penelitian dan analisis maka dari pembahasan disimpulkan bahwa:

1. Terdapat hipotesis yang diterima yaitu persepsi kegunaan terhadap kepuasan pengguna, kualitas sistem terhadap kepuasan pengguna dan persepsi kegunaan, persepsi kemudahan penggunaan terhadap kepuasan pengguna dan ditolak dari beberapa variabel yang telah diuji dalam penelitian ini ialah kualitas informasi terhadap kepuasan pengguna dan persepsi kegunaan dan persepsi kemudahan penggunaan terhadap persepsi kegunaan.

2. Persepsi kegunaan berpengaruh kepada kepuasan pengguna. Hal ini dibuktikan dengan diterima hipotesis ini dimana nilai $t_{\text {statistik }}>$ dari $t_{\text {Tabel }}$ dengan nilai koefisien sebesar 0.234892 .

3. Kualitas sistem berpengaruh terhadap persepsi kegunaan dan kepuasan pengguna dengan ditunjukannya hasil $t_{\text {statistik }}>t_{\text {Tabel }}$ dan tingginya nilai dari indikator tersebut.

Informasi yang terdapat didalam situs sulit dipahami dengan dibuktikannya, kualitas informasi tidak berpengaruh terhadap kepuasan pengguna dan persepsi kegunaan yang ditunjukan dengan $t_{\text {statistik }}>t_{\text {Tabel }}$ yang lebih rendah.

Untuk mendapatkan hasil pengukuran yang lebih baik, maka penelitian selanjutnya menggunakan variabel yang lebih detail mengenai usability dalam web belanja online serta sampel web yang semakin beragam supaya memperkuat pengalaman pengguna dalan situs belanja online. 


\section{DAFTAR PUSTAKA}

[1] A. Molla and P. S. Licker, "ECommerce adoption in developing countries: A model and instrument," Inf. Manag., 2005, doi: 10.1016/j.im.2004.09.002.

[2] F. Brecht, K. Schäfer, A. Baumann, and O. Günther, "Shopping online determining consumer acceptance of online shops," in 17th Americas Conference on Information Systems 2011, AMCIS 2011, 2011, vol. 2, pp. 10031011.

[3] S. Kurnia and A. J. Chien, "The acceptance of online grocery shopping," BLED 2003 Proc., p. 52, 2003.

[4] E. Constantinides, "Influencing the online consumer's behavior: The Web experience," Internet Research. 2004, doi: 10.1108/10662240410530835.

[5] A. Khatibi, A. Haque, and K. Karim, "ECommerce: A study on Internet shopping in Malaysia," J. Appl. Sci., 2006, doi: 10.3923/jas.2006.696.705.

[6] A. Rai, S. S. Lang, and R. B. Welker, "Assessing the validity of IS success models: An empirical test and theoretical analysis," Inf. Syst. Res., 2002, doi: 10.1287/isre.13.1.50.96.

[7] L. Zhou, L. Dai, and D. Zhang, "Online shopping acceptance model: a critical survey of consumer factors in online shopping," J. Electron. Commer. Res., 2007.

[8] W. H. DeLone and E. R. McLean, "Measuring e-commerce success: Applying the DeLone and McLean Information Systems Success Model," Int. J. Electron. Commer., vol. 9, no. 1, pp. 31-47, 2004, doi: 10.1080/10864415.2004.11044317. 